R.V. Zaitsev, M.V. Kyrychenko, A.V. Kholod, L.V. Zaitseva, D.S. Prokopenko, G.S. Khrypunov

\title{
CALCULATION OF OPERATING PARAMETERS OF HIGH-VOLTAGE POWER TAKE-OFF SYSTEM FOR THE PHOTOVOLTAIC FACILITY
}

\begin{abstract}
Purpose. To ensure maximum production of electric power by photovoltaic vacilities, in addition to using highly efficient photovoltaic modules equipped with solar radiation concentrators must use a highly effective power take-off system. This paper is inscribed to solving the problem of a highly efficient and economic power take-off system development. Methodology. To solving the problem, we implemented three stages. On the first stage examines the dependence of electrical power from the intensity of the incident solar radiation. Based on this, the second stage is calculated the DC-DC converter resonant circuit and its working parameters, and developed circuit diagram of DC-DC converter. On the third stage, we carry out an analysis of power take-off system with step up DC-DC converter working. Results. In this paper, we carry out the analysis of working efficiency for photovoltaic facility power take-off system with step-up boost converter. The result of such analysis show that the efficiency of such system in a wide range of photovoltaic energy module illumination power is at 0.92, whereas the efficiency of classic power take-off systems does not exceed 0.70. Achieved results allow designing a circuit scheme of a controlled bridge resonant step-up converter with digital control. Proposed scheme will ensure reliable operation, fast and accurate location point of maximum power and conversion efficiency up to 0.96. Originality. Novelty of proposed power take-off system solution constitute in implementation of circuit with DC-DC converters, which as it shown by results of carrying out modeling is the most effective. Practical value. Practical implementation of proposed power take-off system design will allow reducing losses in connective wires and increasing the efficiency of such a system up to $92.5 \%$ in wide range of photovoltaic energy modules illumination. References 7, tables 3, figures 4.
\end{abstract}

Key words: photovoltaic module, step-up converter, power take-off system, photovoltaic facility, efficiency.

Проведен анализ работы системы отбора мощности фотоэлектрической станции с использованием повыщающего преобразователя. Показано, что коэффициент полезного действия такой системы в широком диапазоне освещенности фотоэлектрического модуля находится на уровне 0,92, тогда как эффективность классических систем отбора мощности не превышает 0,70. Разработана принципиальная электрическая схема регулируемого мостового резонансного повыщающего преобразователя с цифровым управлением, обеспечивающая надежность работы, быстрое и точное нахождение точки максимальной мощности и эффективность преобразования до 0,96. Библ. 7, табл. 3 , рис. 4 .

Ключевые слова: фотоэнергетический модуль, повышающий преобразователь, система отбора мощности, фотоэлектрическая станция, коэффициент полезного действия.

Introduction. To ensure maximum production of photovoltaic facility (PVF), in addition to using highly efficient photovoltaic modules (PVM) equipped with solar radiation concentrators it is necessary to use a highly effective power take-off system (PTOS) [1]. The most important part of the PTOS is a DC-DC converter which enhances increase of DC voltage generated in the operation of PVM for its further high-efficiency transmission and transformation [2, 3]. Here, because depending on the daily change of solar radiation the electrical power produced by PVM also changes, the structural optimization solutions of DC-DC converters and PTOS should be made taking into account the full range of electrical power that is converted. Optimization of constructive and technological solutions of all components of system converting solar energy into electricity of power frequency will increase the efficiency of PVF and by cumulative energy and economic indicators to achieve its competitiveness in the domestic and global market.

Problem definition. Based on the above, the aim of the work is to develop a circuit and constructive decisions and calculation of the operating parameters of high-voltage power take-off system of photovoltaic facility. In the first phase the dependence of electrical power of PVM on the intensity of the solar radiation is investigated. Based on this, in the second phase calculation of the resonance circuit of a DC-DC converter and the parameters of its work is conducted, a circuit diagram of a DC-DC converter is developed. In the third stage analysis of operation of the PTOS using a DC-DC step-up converter is carried out.

The experimental technique. Measurements of short circuit current $\left(I_{S C}\right)$, open circuit voltage $\left(U_{O C}\right)$, working $\left(I_{W}\right)$ and maximum $\left(P_{M A X}\right)$ electrical power and efficiency of standard industrial designs of PVM of Chinese production are carried out at power of solar radiation from 1000 to $2000 \mathrm{~W} / \mathrm{m}^{2}$ that permits to simulate their performance when using concentrators. Measuring these quantities was conducted by the method of loading lighting current-voltage characteristics using the developed and produced stand, block diagram and external view of which are shown in Fig. 1.

Stand for PVM investigations includes: investigated PVM (1), control unit (2), pulse lighter based on xenon flash lamps (3), store of the load resistance (4) with electronic commutation using MOSFET-transistors, and digital oscilloscope to record experimental data (5).

For use as a load resistance a shop of load resistance was designed and manufactured switching individual resistors in which is carried out by using modern MOSFET transistors IRFZ48Z type which have in the open state very small $(0.011-0.012 \Omega)$ and stable resistance of the channel, and do not make thus a significant error in the value of the load resistance, even when measuring the short-circuit current. Registration of 
voltage drop on the load resistance was carried out with a digital oscilloscope RIGOL DS1052E which has the ability to connect directly to a PC.

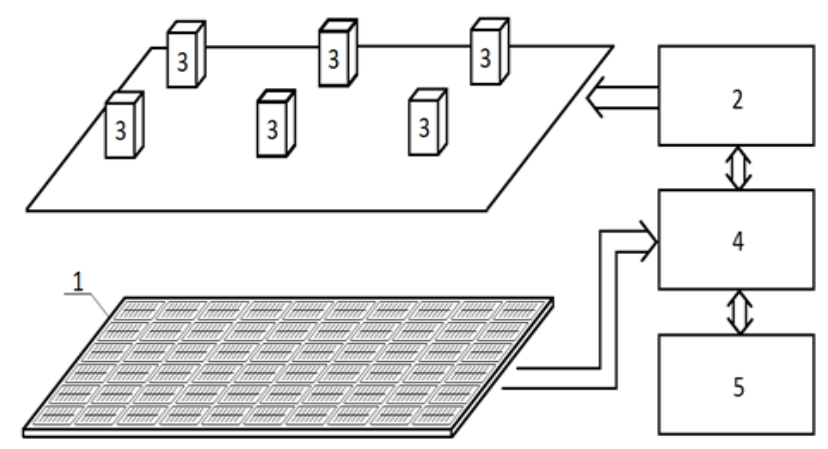

$a$

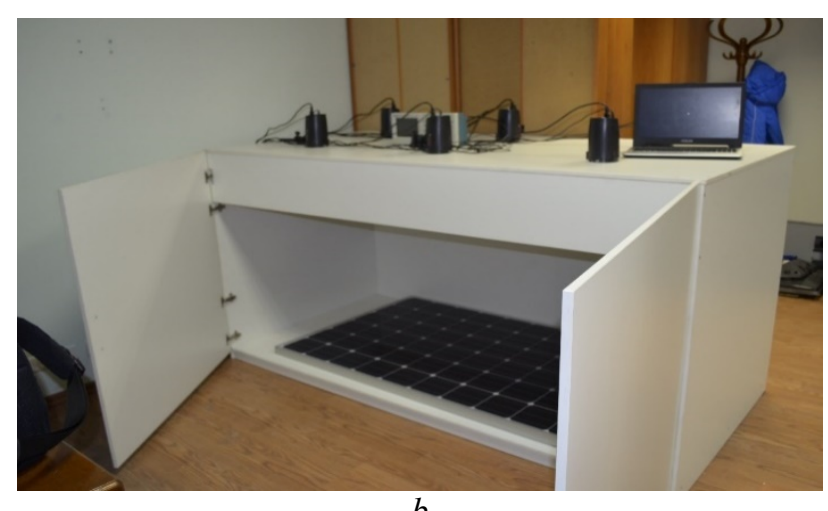

$b$

Fig. 1. Block diagram $(a)$ and external view $(b)$ of the stand for PVM investigations

The operation principle of this stand is as follows. At pulse irradiation from lighter the PVM generates a photocurrent, the duration of amplitude value of its force approximately corresponds to the length of the main phase of the lamp-flash combustion which is about $1 \mathrm{~ms}$. Photocurrent amplitude value power dividing into diode component flowing through the shunt resistance value, and amplitude of the current flowing in the load resistance 4 generates the voltage drop in the load resistance which is registered by a memory digital oscilloscope 5, which operates in sweep waiting mode.

To check the temperature of the PVM in the process of measurements directly to PVM a thermocouple were connected. Determination and adjustment of the radiation power on the front surface of the PVM in the range 1000$2000 \mathrm{~W} / \mathrm{m}^{2}$ was carried out using a standard photoelectric converter that has a known value of short circuit current at the radiation power of $1000 \mathrm{~W} / \mathrm{m}^{2}$. Investigation by the described technique was consistently performed for the values of the radiation power: $1100,1200,1300,1400$, $1500,16001700,1800,1900,2000 \mathrm{~W} / \mathrm{m}^{2}$ and repeated for three experimental samples of PVM.

\section{Results and discussion.}

1. The influence of radiation power on the efficiency of the power module.

Typical results of investigations of experimental samples of PVM are presented in Table 1. Fig. 2 shows built on the basis of the obtained data compiled charts of dependencies of open circuit voltage, short circuit current, maximum power and efficiency on the radiation power on the front surface of PVM. From the results of investigations of experimental samples of PVM it can be concluded that for the investigated samples at the radiation intensity $1500-1800 \mathrm{~W} / \mathrm{m}^{2}$ the typical value of the open circuit voltage is $37.5 \mathrm{~V}$, short circuit current value is 11-13 A, value of maximum power up to $440 \mathrm{~W}$ at voltage in the operating point at least $33 \mathrm{~V}$ providing the photovoltaic module efficiency of at least $16.8 \%$.

Table 1

Output parameters which are characteristic for investigated

PVM samples determined at different radiation power $\left(P_{I}\right)$ on the front surface of PVM

\begin{tabular}{|c|c|c|c|c|c|}
\hline$P_{\mathrm{I}}, \mathrm{W} / \mathrm{m}^{2}$ & $U_{\mathrm{OC}}, \mathrm{V}$ & $I_{\mathrm{SC}}, \mathrm{A}$ & $I_{\mathrm{W}}, \mathrm{A}$ & $P_{\mathrm{MAX}}, \mathrm{W}$ & $\begin{array}{c}\text { Efficiency, } \\
\%\end{array}$ \\
\hline 1000 & 36.99 & 7.68 & 7.37 & 241.49 & 16.54 \\
\hline 1100 & 37.12 & 8.45 & 8.11 & 266.65 & 16.60 \\
\hline 1200 & 37.24 & 9.21 & 8.85 & 291.80 & 16.65 \\
\hline 1300 & 37.39 & 9.98 & 9.58 & 317.08 & 16.71 \\
\hline 1400 & 37.51 & 10.76 & 10.33 & 342.96 & 16.78 \\
\hline 1500 & 37.60 & 11.54 & 11.08 & 368.99 & 16.84 \\
\hline 1600 & 37.74 & 12.29 & 11.80 & 394.48 & 16.88 \\
\hline 1700 & 37.86 & 13.03 & 12.50 & 419.16 & 16.89 \\
\hline 1800 & 37.59 & 13.83 & 13.28 & 441.97 & 16.81 \\
\hline 1900 & 37.28 & 14.60 & 14.01 & 462.45 & 16.67 \\
\hline 2000 & 36.98 & 15.33 & 14.71 & 481.61 & 16.50 \\
\hline
\end{tabular}

It should be noted that the use of experimental models of PVM at low concentrated solar radiation is justified because it is at the radiation power $1700 \mathrm{~W} / \mathrm{m}^{2}$ investigated PVM reach maximum efficiency of $16.89 \%$. An additional advantage of using low concentrated radiation is to increase the maximum power produced by PVM to $419 \mathrm{~W}$ which is 1.7 times more than the value of specified characteristic of the classic solar panels.

Use of low concentrated solar radiation is also an additional argument in favor of equipping each PVM by a step-up DC-DC converter at the development of PTOS as the operating current of PVM at radiation power 1700 $\mathrm{W} / \mathrm{m}^{2}$ reaches $13 \mathrm{~A}$ almost twice exceeding the same value at the radiation power $1000 \mathrm{~W} / \mathrm{m}^{2}$ which if operation of PTOS in traditional way will cause additional losses in the connecting cables or lead to the need of significant investment to equip a photovoltaic facility by cables of enlarged section.

2. Development of a step-up DC-DC converter for the high effective PTOS.

In developing a step-up DC-DC converter as reference parameters obtained in the study of series of PVM are used (Table 1).

2.1. Calculation of a resonant DC-DC circuit and operating parameters of converter.

Conversion gain of the adjustable bridge resonant converter: 


$$
G=K \cdot n,
$$

where $K$ is the conversion gain of the resonant LLC circuit; $n$ is ratio of secondary winding turns to the number of turns of the primary winding of the transformer TR1.
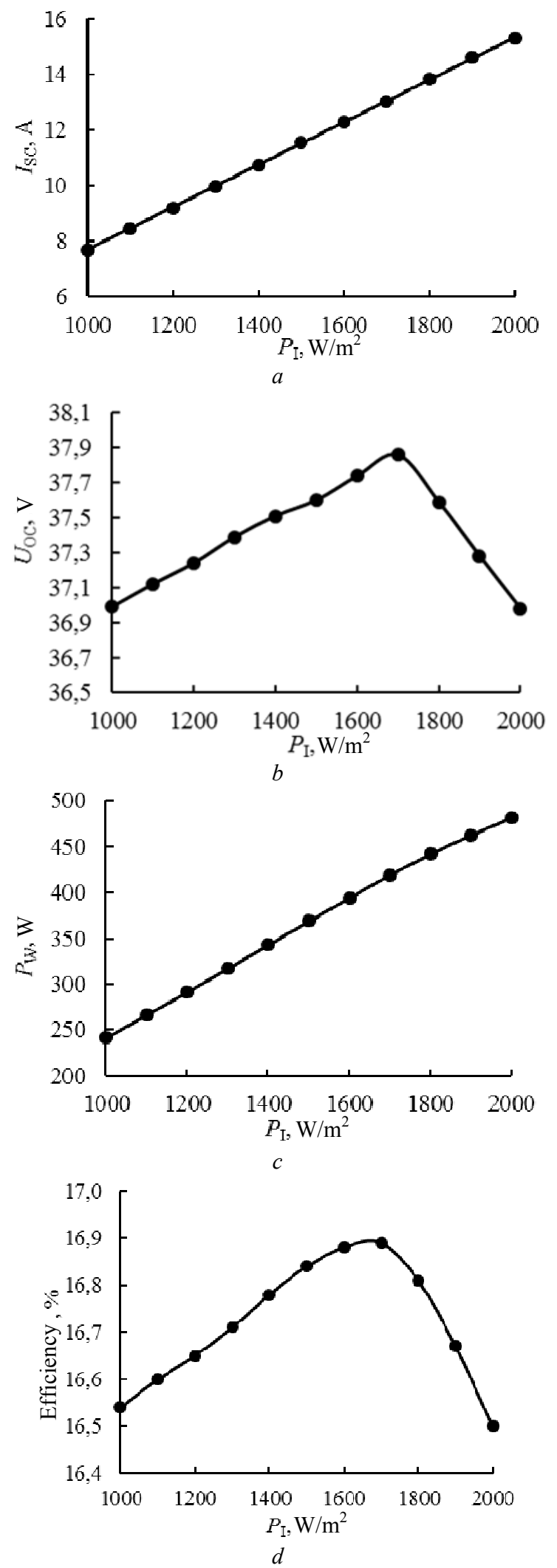

Fig. 2. Typical dependency graphs of short-circuit current $(a)$, open circuit voltage $(b)$, maximum power $(c)$ and efficiency $(d)$ of investigated PVM on radiation power on the front surface
Since the resonant converter has a maximum efficiency at $K=1$, we calculate $n$ from the condition of maximum efficiency in nominal operation mode of the converter:

$$
n=\frac{U_{\text {in.nom. }}}{U_{\text {out.nom. }}}=\frac{30}{630}=\frac{1}{21},
$$

where $U_{\text {in.nom. }}$ is the nominal input voltage of the converter; $U_{\text {out.nom. }}$ is the nominal output voltage of the converter.

Conversion gain of the resonant LLC circuit should have maximal value $K_{\max }$ at the combination of the minimal input $\left(U_{\text {in.min. }}\right)$ and maximal output $\left(U_{\text {out.max. }}\right)$ voltage, and minimal value $K_{\min }$ at the combination of maximal input $\left(U_{\text {in.max. }}\right)$ and minimal output $\left(U_{\text {out.min. }}\right)$ voltage:

$$
\begin{aligned}
& K_{\text {max }}=n \cdot \frac{U_{\text {out.max. }}}{U_{\text {in.min. }}}=\frac{1}{21} \cdot \frac{700}{23} \approx 1,45 ; \\
& K_{\text {min }}=n \cdot \frac{U_{\text {out.min. }}}{U_{\text {in.max. }}}=\frac{1}{21} \cdot \frac{600}{42} \approx 0,68 .
\end{aligned}
$$

To calculate the parameters of the resonant LLC circuit we use the equivalent circuit of the resonant circuit [3-5]. For the presented equivalent circuit the conversion gain of the resonant LLC circuit is described by:

$$
K=\left|\frac{U_{\text {in }}}{U_{\text {out }}}\right|=\frac{F_{x}^{2}(m-1)}{\sqrt{\left(m F_{x}^{2}-1\right)+F_{x}^{2}\left(F_{x}^{2}-1\right)^{2}(m-1)^{2} Q^{2}}},
$$

where

$Q=\frac{\sqrt{\frac{L_{r}}{C_{r}}}}{R_{a c}}$ is the quality factor; $R_{a c}=\frac{8}{\pi^{2}} n^{-2} \frac{U_{\text {out }}}{I_{\text {out }}}$ is the superficial load resistance; $U_{\text {in }}$ is the input voltage of the converter; $U_{\text {out }}$ is the output voltage of the converter; $I_{\text {out }}$ is the output current of the converter; $F_{x}=\frac{f_{s}}{f_{r}}$ is the normalized frequency of switching transistors; $f_{s}$ is the frequency of switching transistors of the converter; $f_{r}=\frac{1}{2 \pi \sqrt{L_{r} C_{r}}}$ is the resonant frequency of the circuit $L_{r}$ , $C_{r} ; L_{r}$ is the resonant inductance; $C_{r}$ is the resonant capacitance; $m=\frac{L_{r}+L_{m}}{L_{r}}$ is the ratio of the total input inductance of the circuit to the resonant inductance; $L_{m}$ is the inductance of the transformer magnetization.

Minimum superficial load resistance $R_{\text {ac.min }}$. corresponds to the minimum output voltage and maximum output power $\left(P_{\text {in.max. }}\right)$ at the maximum expected efficiency of $98 \%$ :

$$
\begin{gathered}
R_{\text {ac.min. }}=\frac{8}{\pi^{2}} n^{2} \frac{U_{\text {out.min. }}^{2}}{P_{\text {in.max. }} \cdot \eta}= \\
=\frac{8}{3,14^{2}} \cdot 0,047619^{2} \cdot \frac{600^{2}}{300 \cdot 0,98} \approx 2,25 \Omega .
\end{gathered}
$$

The correct calculation of the resonance circuit allows to obtain optimal characteristics of the converter. The algorithm allows for multiple iterations to calculate 
the required parameters of the LLC resonant circuit. Using approximate calculation and refine it using simulations we can obtain quite faithful results at considerable time savings.

Maximum input voltage of the DC-DC converter meets maximal temperature of the PVM, illumination 200 $\mathrm{W} / \mathrm{m}^{2}$, i.e. input power $\left(P_{\text {in.min. }}\right)$ not more than:

$$
\begin{aligned}
P_{\text {in.min. }}(23 \mathrm{~V}) \leq & 23 \mathrm{~V} \cdot I_{\text {in.nom. }} \cdot \frac{200}{1000} \mathrm{~W} / \mathrm{m}^{2}= \\
& =37,6 \mathrm{~W} .
\end{aligned}
$$

The maximum value of $Q$ corresponds to the maximum output current. Output current takes maximum value at minimum output voltage and maximum output power. The value of the superficial minimum load resistance $R_{\text {ac.min. }}=2.25 \Omega$ corresponds to the maximum $Q$ of the LLC circuit, and the maximum conversion gain of the resonant circuit $K_{\max }=1,45$ is required at the input power of $50 \mathrm{~W}$ and output voltage of $700 \mathrm{~V}$. According to the expression for $R_{a c}$, the value of minimal superficial load resistance $R_{a c . m i n}$ is determined for the input voltage of $23 \mathrm{~V}$ :

$$
\begin{gathered}
R_{\text {ac.min. }}(23 V)=\frac{8}{3,14^{2}} \cdot 0,047619^{2} \cdot \frac{600^{2}}{50 \cdot 0,98} \approx \\
\approx 13,5 \Omega .
\end{gathered}
$$

Data for the resonance frequency of $100 \mathrm{kHz}$ obtained by the algorithm calculating the parameters of the resonance circuit in several iterations with test computer modeling are presented in Table 2. The value of the ratio of the total input inductance to resonance one $m=11$.

Table 2

Resonance circuit parameters

\begin{tabular}{|c|c|c|c|c|c|c|}
\hline$U_{\text {in }}, \mathrm{V}$ & $P_{i n}, \mathrm{~W}$ & $K_{\max }$ & $K$ & $R_{\text {ac.max. }}, \Omega$ & $Q_{\max }$ & $F_{x}$ \\
\hline 23 & 50 & 1.45 & 3.13 & 13,5 & 0.113 & 0.33 \\
\hline 30 & 230 & 1.11 & 1.134 & $3,995^{*}$ & $0.383^{*}$ & $0.48^{*}$ \\
\hline 33 & 300 & 1.01 & 1.026 & 2,25 & 0.68 & 0.86 \\
\hline 42 & 300 & 0.79 & 1.026 & 2,25 & 0.68 & 0.972 \\
\hline
\end{tabular}

* Value of $R_{a c \text { min. }}$ corresponds to maximum output voltage and $K_{\max }$.

Choosing the resonant capacitance of $0.94 \mu \mathrm{F}$ at the resonance frequency $F_{r}=110.7 \mathrm{kHz}$ we obtain the resonant inductance value $L_{r}=2.2 \mu \mathrm{H}$ and at $m=10.1$ the transformer inductance of magnetization value $L_{m}=20 \mu \mathrm{H}$.

\subsection{Development of schematic diagram of the DC-}

\section{DC converter.}

Fig. 3 shows the functional diagram of the DC-DC converter. Photovoltaic module voltage comes to the input of the DC-DC converter. Formation of converter parameters $\mathrm{r}$ and switching transistors are carried out by using a digital microcontroller MC. The control signal comes to gates of transistors VT1 - VT4 from the MC by drivers Dr.1 - Dr.4. Transistors within each arm of the bridge are switched simultaneously. Drivers and microcontrollers supply is carried out through a stabilized step-down DC converter of own needs. MC measures output current of the PVM using shunt R3 and amplifier, output voltage of the FEM through divider on the resistors $\mathrm{R} 1$ - R2. MC at the outputs G1 and G2 forms two counter-phase meanders for switching transistor with the required frequency and time delay between switching diagonals of the bridge («dead» time). Voltage of the midpoint of the half-bridge of transistors VT1 and VT2 is used in determining of adaptive «dead» time (minimum required one) for maximum efficiency of the converter through divider on the resistors R4 and R5 enters to the comparator of MC. Additional transformer winding N3 connected to the rectifier bridge VD1 is used to control the output voltage and, together with the signal voltage of the midpoint of the half-bridge, is involved in the detection algorithm of approach to the capacitive current character of the resonant LLC circuit. Detection of approaching to the capacitive current character of the resonance circuit is essential when starting of the converter, as well as at relatively sharp changes of voltage on the output converter - a DC network $600-700 \mathrm{~V}$.

The resonant LLC circuit is formed by a choke L1, a capacitor $\mathrm{C} 1$ and a transformer $\mathrm{T} 1$. The resonant inductance includes the inductance of the choke L1 and scattering inductance of the transformer T1. The output voltage from the transformer enters to the rectifier formed by added diode VD2 and the capacitor C3. Output voltage of the rectifier is the output voltage of the converter.

Tracking the point of maximum power of the PVM is carried out by microcontroller using the algorithm «Perturbations and monitoring» [6]. The microcontroller calculates the input power of the converter, then for a small amount it changes the input resistance by the change of the frequency of switching transistors, thus the input voltage changes, and calculates the power, and if the power increases - the controller continues to change the voltage in the same direction until the power stops growing. Digital converter control enables to realize an algorithm of maximum power point tracking «Perturbations and surveillance», forming the adaptive «dead» time, current detection of capacitive nature of the bridge load. With the microcontroller implementation of an information cable or wireless network, for example, RS-485 or ZigBee for monitoring of parameters of PVM converters, providing timely information about the failure, and so on becomes possible.

\subsection{A schematic diagram of the DC-DC} converter.

The converter consists of three functional blocks.

Source of power supply for own needs (SON) is designed to form a stabilized supply voltage $3.3 \mathrm{~V}$ and voltage of converter's transistors drivers supply $12 \mathrm{~V}$. SON consists of two consecutive stages of step-down pulse DC converters without galvanic isolation. SON has high efficiency and stabilizes the output voltage in a wide input voltage range.

Controller. As a microcontroller a 32-bit ARM Cortex M-4 is used. Feedback signals after the conversion of levels filtering enter to the ADC of the microcontroller. The signal of current from the shunt is increased by the differential amplifier to the required level and then supplied to the ADC. On the chip DA6 the ADC voltage reference voltage is performed. Comparators are made on high-speed integrated circuits LMV7235M5. Transistors' control signals come to the circuit G1 and G2 on drivers inputs. 


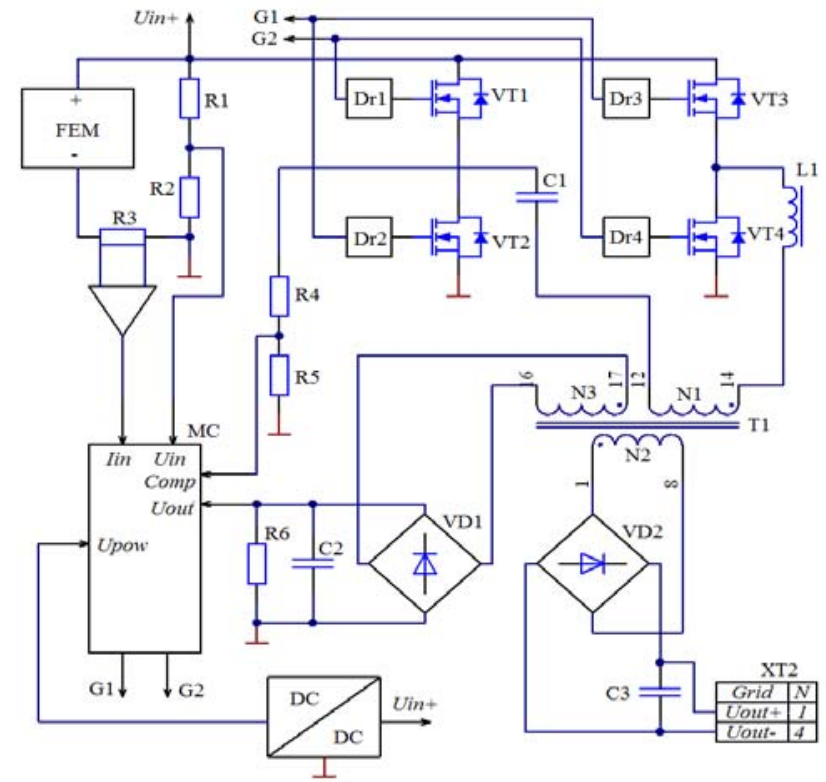

Fig. 3. Functional electric circuit of the DC-DC converter

The converter consists of: four transistors MOSFET VT1 - VT4; two drivers of a half-bridge on chips DA7, DA8; capacitors of a supply circuit; RLC resonant circuit on the choke L4, transformer T1, capacitors C46, C47; signal rectifier on diodes VD - VD12; output rectifier on diodes VD13 - VD16 and capacitors S52, S53. As a transistor bridge high-speed MOSFET transistors with low gate charge and open channel resistance of $2.8 \mathrm{~m} \Omega$ are used. In the input rectifier diodes based on silicon carbide are used which allows significantly increase efficiency in the frequency range of switching transistors above resonance frequency value due to the absence of losses on reverse recovery of diodes based on silicon carbide.

3. Analysis of the power take-off system operation with DC-DC converter utilization.

To significantly reducing power losses [7] in PTOS utilization in its composition previously developed DCDC converters that will reduce the currents flowing within the PTOS and, accordingly, proportionally the square of the current, decrease power losses, can lead. In the case of the PTOS development using DC-DC converters, the system will be divided into the following areas, which will experience losses in PTOS:

- area of the cable connection of the PVM and DC-DC converter $\left(P_{\text {loss.PVM-DC }}\right)$;

- directly DC-DC converter $\left(P_{\text {loss.DC }}\right)$;

- area of the cable connection of the DC-DC converter and inverter $\left(P_{\text {loss.DC-Inv }}\right)$;

- inverter $\left(P_{\text {loss.Inv }}\right)$.

Calculated losses for each of areas and calculated efficiency of the PTOS (Efficiency ${ }_{P T O S}$ ) as a dependence o the PVM current $\left(I_{P V M}\right)$ are presented in Table 3 and Fig. 4.
Table 3

Parameters of power losses and efficiency calculated for PTOS with utilization of the DC-DC converter

\begin{tabular}{|c|c|c|c|c|c|}
\hline $\begin{array}{c}I_{\text {PVM }}, \\
\mathrm{A}\end{array}$ & $\begin{array}{c}P_{\text {loss.PVM- }} \\
D_{C}, \mathrm{~W}\end{array}$ & $\begin{array}{c}P_{\text {loss. } D C}, \\
\mathrm{~W}\end{array}$ & $\begin{array}{c}P_{\text {loss. DC- }} \\
\text { Inv }, \mathrm{W}\end{array}$ & $\begin{array}{c}P_{\text {loss. Inv }}, \\
\mathrm{W}\end{array}$ & $\begin{array}{c}\text { Efficiency } \\
\%\end{array}$ \\
\hline 7.68 & 0.57 & 10.72 & 4.78 & 351.86 & 92.68 \\
\hline 8.45 & 0.69 & 11.83 & 5.92 & 388.35 & 92.66 \\
\hline 9.21 & 0.82 & 12.94 & 6.84 & 424.83 & 92.63 \\
\hline 9.98 & 0.96 & 14.06 & 8.24 & 461.52 & 92.61 \\
\hline 10.76 & 1.11 & 15.21 & 9.72 & 499.36 & 92.59 \\
\hline 11.54 & 1.27 & 16.34 & 10.92 & 536.37 & 92.57 \\
\hline 12.29 & 1.45 & 17.48 & 12.64 & 573.68 & 92.54 \\
\hline 13.03 & 1.64 & 18.58 & 14.46 & 609.94 & 92.52 \\
\hline 13.83 & 1.84 & 19.57 & 15.92 & 642.34 & 92.49 \\
\hline 14.60 & 2.05 & 20.45 & 17.46 & 671.29 & 92.46 \\
\hline 15.33 & 2.27 & 21.27 & 18.48 & 697.98 & 92.44 \\
\hline
\end{tabular}

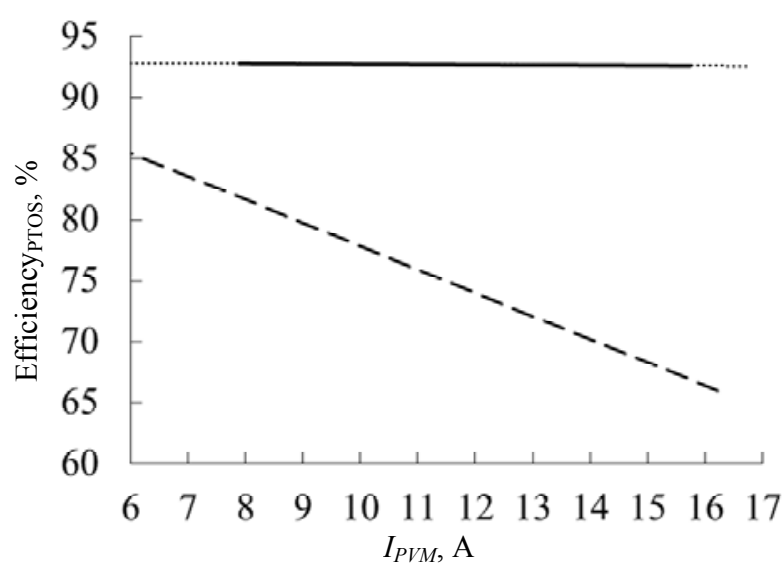

Fig. 4. Dependence of the calculated efficiency of the PTOS of the PVF with utilization of the DC-DC converters (solid line) in the comparison with PVF without DC-DC converters (dotted line)

\section{Conclusions.}

1. From the results of the experimental investigations of photovoltaic modules on the intensity of solar radiation it is found that at the radiation power of $1700 \mathrm{~W} / \mathrm{m}^{2}$ the investigated PVM reach maximum efficiency of $16.89 \%$ and maximum power produced by photovoltaic modules reaches $419 \mathrm{~W}$ that 1.7 times more that the indicated value which is character for the classic solar panels.

2. Based on experimental data, the calculation of the resonance circuit of the DC-DC converter for use in high voltage power take-off system of the photovoltaic facility and the parameters of its operation. The main features of the developed schematic diagram of the DC-DC converter circuit is controlled using the bridge resonant converter are the use of the circuit of adjustable bridge resonant converter and allows utilization of digital control that permits to achieve a conversion efficiency of $95.8 \%$.

3 . The carried out analysis of the system for selecting the photovoltaic facility power using developed DC-DC converters has shown that the efficiency of the system in a wide range of illumination of the PVM is about $92 \%$, that is significantly more than for the classical power take-off systems, whose effectiveness is about $70 \%$. 


\section{REFERENCES}

1. Kriukov Yu.A., Zaitsev A.Ye., Feshchenko A.A., Gorshkov A.V. Influence of operating temperature on efficiency of silicon photovoltaic devices. International Journal of Applied Engineering Research, 2015, vol.10, no.15, p.35446-35450.

2. Rozanov Yu.K., Baranov N.N., Antonov B.M., Efimov E.N., Solomatin A.V. Power electronics in systems with nontraditional power sources. Electrical Technology Russia, 2002, no.3, pp. 20-28.

3. Melyoshin V., Ovchinikov D. Upravlenie tranzistornymi preobrazovatelyami elektroenergii [Management transistor power converters]. Moscow, Technosfera Publ., 2011. 576 p. (Rus).

4. Yilei Gu, Lijun Hang, Huirning Chen, Jun Li, Zhaoming Qian, Jun Li. A simple structure of LLC resonant DC-DC converter for multi-output applications. Twentieth Annual IEEE Applied Power Electronics Conference and Exposition, 2005, vol.3, pp.1485-1490. doi: 10.1109/apec.2005.1453229.

5. Abdel-Rahman S. Resonant LLC converter: Operation and Design 250W 33Vin 400Vout Design Example. Infineon Technologies Application Note AN 2012-09 V1.0, 2012.

6. Freeman D. Introduction to photovoltaic systems maximum power point tracking. Texas Instruments Application Report SLVA446, 2010.

7. Bogatyirev N.I., Grigorash O.V., Kurzin N.N., Strelkov Yu.I., Telnov G.V., Tropin V.V. Preobrazovateli elektricheskoy energii: osnovyi teorii, rascheta i proektirovaniya [Converters of electric power: the basic theory, calculation and design]. Krasnodar, BI Publ., 2002. 358 p. (Rus).

Received 21.01.2015

R.V. Zaitsev ${ }^{1}$, Candidate of Technical Science, Associate

Professor,

M.V. Kyrychenko ${ }^{1}$, Candidate of Technical Science, Senior Research Scientist

A.V. Kholod ${ }^{2}$, Senior Engineer,

L.V. Zaitseva ${ }^{3}$, Candidate of Technical Science, Senior

Instructor,

D.S. Prokopenko ${ }^{1}$, Master of Science,

G.S. Khrypunov ${ }^{1}$, Doctor of Technical Science, Professor,

${ }^{1}$ National Technical University «Kharkiv Polytechnic Institute», 21, Kyrpychova Str., Kharkiv, 61002, Ukraine.

e-mail: zaitsev.poman@gmail.com, kirichenko.mv@gmail.com

${ }^{2}$ Company «ELAKS»,

1, build. 12, Ac. Proskura Str., Kharkiv, 61085, Ukraine.

e-mail: underholod@mail.ru

${ }^{3}$ Zhukovsky National Aerospace University «Kharkiv Aviation Institute»,

17, Chkalova Str., Kharkiv, 61000, Ukraine.

How to cite this article:

Zaitsev R.V., Kyrychenko M.V., Kholod A.V., Zaitseva L.V., Prokopenko D.S., Khrypunov G.S. Calculation of operating parameters of high-voltage power take-off system for the photovoltaic facility. Electrical engineering \& electromechanics, 2016, no.4, pp. 63-68. doi: 10.20998/2074-272X.2016.4.09. 